\title{
Effect of Annealing Temperature on the Structural and Optical Properties of $\mathrm{TiO}_{2}$ Thin Film Prepared by Sol-gel Method
}

\author{
F. U. Khan ${ }^{1}$, M. Zubair ${ }^{2}$, I. Khan ${ }^{1}$, M. Z. Ansar ${ }^{3 *}$, M. K. Alamgir ${ }^{3}$, and S. Nadeem ${ }^{3}$ \\ ${ }^{1}$ University of Peshawar, Peshawar, Pakistan \\ ${ }^{2}$ University of the Punjab, Lahore, Pakistan \\ ${ }^{3}$ National Institute of Vacuum Science \& Technology, NCP Complex, Shahdra Valley Road, \\ Islamabad, Pakistan
}

Received 31 March 2016, accepted in final revised form 9 August 2016

\begin{abstract}
The effect of annealing temperatures on the surface morphology and optical properties of titanium dioxide $\left(\mathrm{TiO}_{2}\right)$ thin films deposited by spin coating on Silicon substrate was studied. The $\mathrm{TiO}_{2}$ thin films deposited onto silicon substrates were annealed at different temperatures. The structural and optical properties were studied using scanning electron microscopy (SEM), X-ray diffraction technique (XRD) and optical ellipsometer. The results indicated that the structural properties of the $\mathrm{TiO}_{2}$ thin films were changed with the increase in annealing temperature. The SEM investigation showed that as annealing temperature was increased, the grain and pores size were increased. The XRD patterns of the studied samples showed that rutile phase were found in a sample annealed at high temperature. The ellipsometry investigation shows that the refractive index increased while energy band gap decreased with the annealing temperature. The results showed that surface porosity, optical properties and surface morphology of $\mathrm{TiO}_{2}$ could be affected by changing the annealing temperature.
\end{abstract}

Keywords: Thin film; Sol-gel; Spin coating; Annealing; $\mathrm{TiO}_{2}$.

(c) 2016 JSR Publications. ISSN: 2070-0237 (Print); 2070-0245 (Online). All rights reserved. doi: http://dx.doi.org/10.3329/jsr.v8i3.27195 J. Sci. Res. 8 (3), 267-272 (2016)

\section{Introduction}

Titanium Dioxide, titania, $\mathrm{TiO}_{2}$ is a promising wide band gap $(\mathrm{E} \mathrm{g}>3 \mathrm{eV}$ ) oxide material, and due to its unique properties such as non-toxic, inexpensive, highly photoactive, easily synthesized and handled, highly photostable, it has been subjected to extensive academic and technological research for decades $[1,2]$.

\footnotetext{
Corresponding author: zakaphy@gmail.com
} 
$\mathrm{TiO}_{2}$ films are applicable for storage capacitor in integrated electronic, protective coatings, and optical components because of its high dielectric constant, hardness, and transparency. In order to improve the photocatalytic activity and optical absorption; study of nanosized $\mathrm{TiO}_{2}$ is main focus [2]. $\mathrm{TiO}_{2}$ is a large band gap semiconductor with exceptional stability that improves its importance in industrial applications. $\mathrm{A} \mathrm{TiO}_{2}$ thin film has a high refractive index due to which it has broad applications in optical coatings and waveguides [3]. $\mathrm{TiO}_{2}$ normally occurs in three crystalline polymorphs: rutile (tetragonal), anatase (tetragonal), and brookite (orthorhombic) [4]. Both Anatase and Rutile phases are more common than the Brookite phase and have wide applications. Rutile is the most stable phase because of its high refractive index and density [5]. Particular phase formation of $\mathrm{TiO}_{2}$ depends on the starting material nature, its composition, deposition technique, and annealing temperatures. $\mathrm{TiO}_{2}$ thin films can be papered by different methods including electron beam evaporation, Sputtering, Pulse Laser Deposition, Chemical Vapor Deposition, Polymer technique and sol-gel method [6-11]. The sol-gel is a quick and easy technique to produce homogeneous organic films with large surface areas. It is less demanding in terms of equipment and is thus less costly $[12,13]$. The main objective of this research is to use these thin films as electrodes in dye sensitized solar cells.

\section{Experimental}

The $\mathrm{TiO}_{2}$ films were deposited on Silicon substrates by using spin coating deposition method. The silicon substrates were cleaned with acetone, methanol, and distilled water, followed by drying in an oven. $\mathrm{The}^{\mathrm{TiO}_{2}}$ solution was prepared by mixing $50 \mathrm{~mL}$ deionized water and $3 \mathrm{~mL}$ acetic acid. Then one gram of $\mathrm{TiO}_{2}$ nanopowder was added into the solution while vigorously stirring the solution. After that triton X-100 (one drop) was also added into the above solution. Then the solution was stirred continuously for $24 \mathrm{~h}$ at room temperature. The Si substrates were placed on spin coater and rpm value was fixed at 3000 . The $\mathrm{TiO}_{2}$ solution was dropped onto the substrates for $10 \mathrm{sec}$. The $\mathrm{TiO}_{2}$ thin films were dried in the oven at $100^{\circ} \mathrm{C}$ for $10 \mathrm{~min}$. After that, the films were annealed at $450^{\circ}, 800^{\circ}$ and $1000^{\circ} \mathrm{C}$ for $1 \mathrm{~h}$ in the furnace in air environment leaving one sample unanealed.

\section{Results and Discussion}

\subsection{Structural characteristics}

The structural and surface characteristics of $\mathrm{TiO}_{2}$ thin films were studied in a scanning electron microscope (SEM). The microstructures of the as deposited sample and after being annealed at different temperatures are shown in the figure below (see Figs. 1a, 1b, 1c and 1d). It has been observed that as deposited $\mathrm{TiO}_{2}$ thin film on silicon substrate has less grain size and pore area. Referring to Fig. 1b, the average grain size and pore area is increased. In Fig. 1c, the average grain size and the pores size of $\mathrm{TiO}_{2}$ thin film is improved in a spherical shape. The average grain size and porosity at $1000^{\circ} \mathrm{C}$ is the highest among the sintered temperatures. This 
shows that by increasing temperature the grain and pore size both increased which is in good agreement with the results by previous reported results $[14,15]$. These results showed that surface porosity and surface morphology of $\mathrm{TiO}_{2}$ could be affected by changing the annealing temperature.

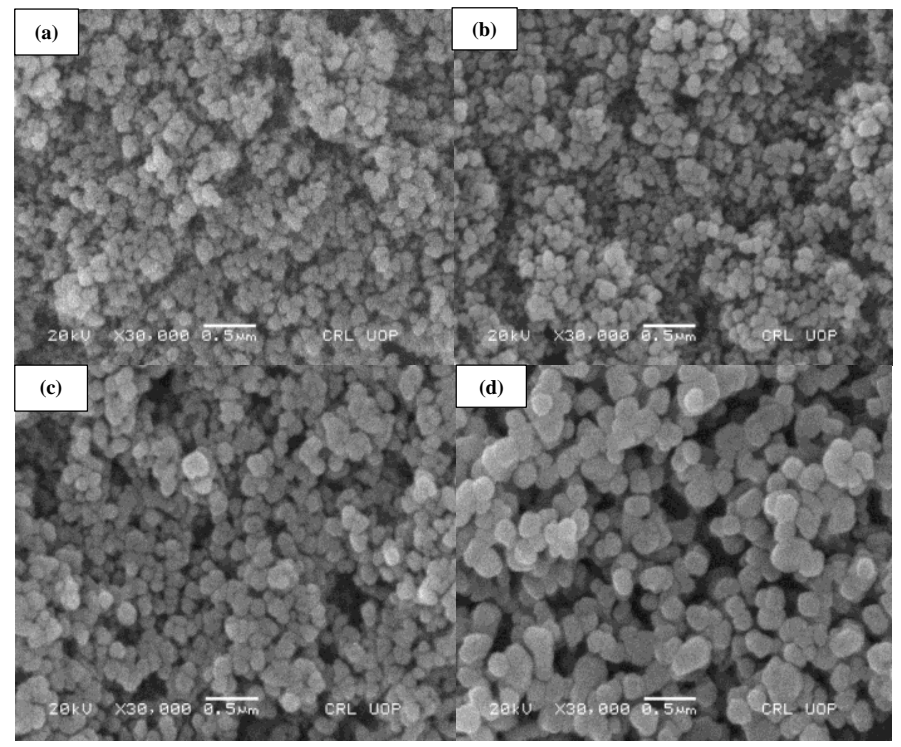

Fig. 1. (a), (b), (c) and (d) SEM images of $\mathrm{TiO}_{2}$ thin films as-deposited and annealed at $450^{\circ}$, $800^{\circ}$ and $1000^{\circ} \mathrm{C}$ using spin coater method at speed of $3000 \mathrm{rpm}$ on silicon substrate respectively.

\subsection{XRD results}

Fig. 2 shows XRD patterns for $\mathrm{TiO}_{2}$ thin films. The spectrum of as deposited film shows well defined diffraction peaks and possesses an Anatase and weekly brookite structure. There is no significant changes occurs in XRD peaks up to $4500^{\circ} \mathrm{C}$. The intensities of the peaks of few $\mathrm{TiO}_{2}$ planes changes slightly with the increase of annealing temperature and become rutile if the annealing temperature reaches to $10000^{\circ} \mathrm{C}$ which is good agreement with the results by Yoo et al. [16]. They reported only rutile structures of the samples annealed above $8000^{\circ} \mathrm{C}$ at $11000^{\circ} \mathrm{C}$ by conventional thermal annealing (CTA) of the $\mathrm{TiO}_{2}$ thin films prepared by $\mathrm{RF}$ magnetron sputtering. It was also observed that at the high annealing temperature $\left(10,000^{\circ} \mathrm{C}\right)$ the intensities of the peaks increase due to which the FWHM of the peaks reduced, and by reducing the FWHM, the crystallite size increased (according to Scherrer formula). These results are in agreement with the SEM data presented above. 


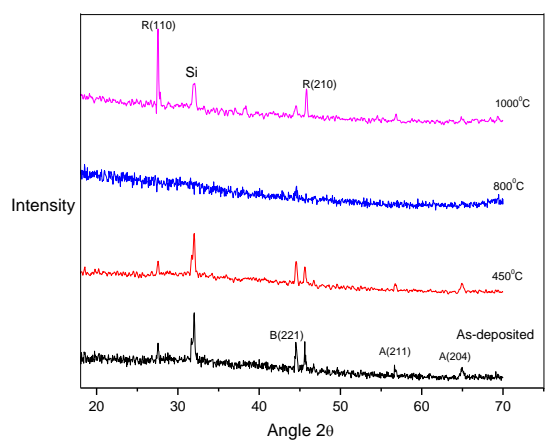

Fig. 2. XRD patterns for the samples as-deposited, annealed at $450^{\circ} \mathrm{C}, 800^{\circ} \mathrm{C}$ and $1000^{\circ} \mathrm{C}$.

\subsection{Optical characteristics}

Optical properties (Refractive index and Band gap energy) were investigated from the data collected from optical Ellipsometer.

In Fig. 3, we show the refractive index (n) at the surface of the samples over the wavelength range of $350-800 \mathrm{~nm}$. Increasing the annealing temperature the gradual increase in the value of " $n$ " can be seen. It can also be seen that the value of " $n$ " decrease with increasing the wavelength. This increase in " $n$ " with annealing temperature is attributed to the increase in packing density and crystallinity of the films which are also evident from the thickness measurement and XRD analysis. These results are in good agreement with the results obtained by Rahman et al. [3] and the results obtained by Kaduory [17] and Al-Obaidi [18].

The energy gap value depends on the films deposition conditions and its preparation method which influences in the crystalline structure [19]. The reason of variation in energy gap is by making variations in the structural and other properties of the deposited films.

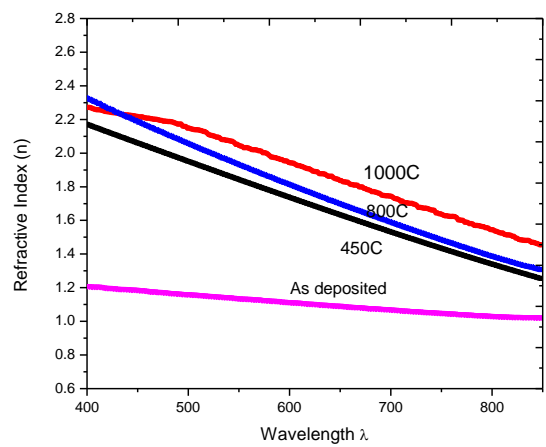

Fig. 3. Variation of Refractive Index with wavelength for different annealed samples. 
Optical Energy Gap $\left(E_{g}\right)$ can be calculated by extrapolating the straight line part of the curves $(\alpha h v)^{2}$ with energy axes $(h v)$ i.e $(\alpha h v)^{2}=0$ we evaluated the band gap of the $\mathrm{TiO}_{2}$ thin films, as shown in Fig. 4. From the Figure it can be observed that $E_{g}$ is decreased with the increase of the annealing temperature. The result obtained is consistent with the reported literature [20]. Annealing led to increased levels of localized near valence band and conduction band and these levels ready to receive electrons and generate tails in the optical energy gap and tails is working toward reducing the energy gap, or can be attributed decrease energy gap to the increased size of particles in the films [21] or we can say that decrease in the bang gap energy occur with increasing the annealing temperature is due to the lowering of interatomic spacing.

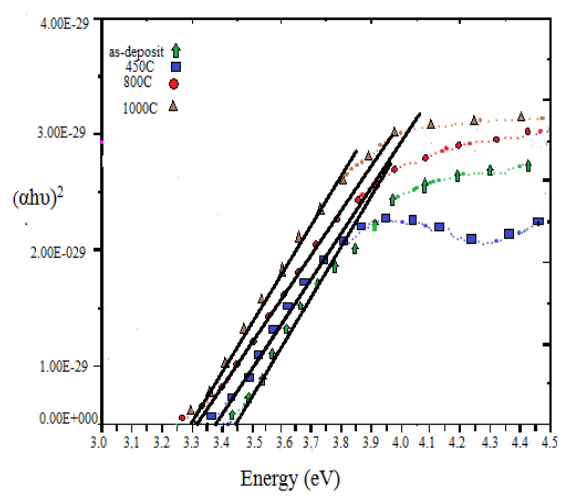

Fig. 4. $(\alpha h v)^{2}$ as a function of photon energy.

\section{Conclusion}

Titanium dioxide $\left(\mathrm{TiO}_{2}\right)$ thin films were deposited by spin coating technique on Silicon (Si) substrates. The effect of annealing temperatures on the surface morphology and optical properties were studied by using SEM and XRD and optical properties were studied by optical ellipsometry. The XRD result indicated that the as the annealing temperature was increased the grain and pore size was increased. The SEM investigation showed that at higher annealing temperature the grains were well shaped i.e. spherical. The optical investigation shows that the value of refractive index and band gap changes with the annealing temperature.

\section{References}

1. Y. Park and K. Kim, Thin Solid Films 484, 34 (2005). http://dx.doi.org/10.1016/j.tsf.2005.01.039

2. A. Burns, G. Hayes, W. Li, J. Hirvonen, J. Demaree, and S. Shah, Mater. Sci. Eng. B 111, 150 (2004). http://dx.doi.org/10.1016/j.mseb.2004.04.008 
3. M. M. Rahman, G. Yu, T. Soga, T. Jimbo, H. Ebisu, and M. M. Umeno, J. Appl. Phys. 88, 4634 (2000). http://dx.doi.org/10.1063/1.1290456

4. O. V. Overschelde, G. Guisbiers, F. Hamadi, A. Hemberg, R. Snyders, and M.Wautelet, J. Appl. Phys. 104, 1 (2008). http://dx.doi.org/10.1063/1.3021161

5. H. Bach and D. Krause, Thin films on Glass, $1^{\text {st }}$ edition (Springer-Verlag GmbH, Berlin, 2003).

6. S. Wang, G. Xia, H. He, K. Yi, and J. Shao, J. Alloys Compd. 431, 287 (2007). http://dx.doi.org/10.1016/j.jallcom.2006.05.091

7. S. Takeda, S. Suzuki, H. Odaka, and H. Hosono, Thin Solid Films 392, 338 (2001). http://dx.doi.org/10.1016/S0040-6090(01)01054-9

8. H. Y. Ha, S.W. Nam, T.H. Lim, I. H. Oh, and S. A Hong, J. Membr. Sci. 111, 81 (1996). http://dx.doi.org/10.1016/0376-7388(95)00278-2

9. L. P. Sheng, C. W. Ping, W. L. Xi, S. M. Da, L. X. Dong, and J. W. Ping, Trans. Nonferrous Met. Soc. China 19, 743 (2009). http://dx.doi.org/10.1016/S10036326(10)60143-4

10. S. N. Karthick, K. Prabakar, A. Subramania, J. J. Jang, and H. Kim, Powder Technol. 205, 36 (2011). http://dx.doi.org/10.1016/j.powtec.2010.08.061

11. K. Bouabid, A. Ihlal, Y. Amir, A. Sdaq, A. Assabbane, Y. Ait-Ichou, A. Outzourhit, E. L. Ameziane, and G. Nouet, Ferroelectrics 372, 69 (2008). http://dx.doi.org/10.1080/00150190802381779

12. C. J. Brinker and G.W. Scherer, Sol-Gel Science (Academic Press, San Diego, 1990).

13. C. Rath, Mohanty, V. Pandey, and N. C. Mishra, J. Phys. D 42, 205101 (2009). http://dx.doi.org/10.1088/0022-3727/42/20/205101

14. S. Nadzirah and U. Hashim, IEEE Regional Symposium on Micro and Nanoelectronics (RSM), 167 (2013). http://dx.doi.org/10.1109/RSM.2013.6706499

15. M. K. Ahmad, M. L. M. Halid, N. A. Rashied, and M. Rusop, J. Sustain. Eng. Env. 1, 17 (2010).

16. D. Yoo, I. Kim, S. Kim, C. H. Hahn, C. Lee, and S. Cho, Appl. Surf. Sci. 253, 3888 (2007). http://dx.doi.org/10.1016/j.apsusc.2006.08.019

17. S. S. Kaduory, A. A. Yousif, A. J. Haider, and K. Z. Yahya, Eng. Technol. J. B 31, 460 (2013).

18. S. S. Al-Obaidi and A. A. Yousif, Ibn Al-Haitham J. Pure Appl. Sci. 26, 143 (2013).

19. M. Brodsky, Amorphous Semiconductors (Springer-Verlag, Berlin, 1979).

20. S. Sankar and K. Gopchandran, Cryst. Res. Technol. 44, 989 (2009). http://dx.doi.org/10.1002/crat.200900073

21. S. Pawar, M. Chougule, P. Godse, D. Jundale, S. Pawar, B. Raut, and V. Patil, J. NanoElec. Phys. 3, 185 (2011). 